\title{
Edukasi Tentang Pemberian Makanan Pendamping ASI
}

\author{
Fatihatul Hayati \\ Prodi DIII Kebidanan STIKes Baiturrahi Jambi \\ Email: fatihatulhayatianam@gmail.com
}

Submitted : 20/11/2019

Accepted: $27 / 11 / 2019$

Published: $31 / 01 / 2020$

\begin{abstract}
Indonesia is included in the group of countries with a high prevalence of stunting (30$39 \%$ ) where this prevalence increased from $36.8 \%$ in 2007 to $37.2 \%$ in 2013. According to UNICEF, the indirect factor causing stunting is parenting (ASI-Exclusive and ASI Complementary Foods/ MP-ASI) are not good. Several studies have suggested that nutritional problems in infants and children are caused by inappropriate breastfeeding and MP-ASI habits. Supplementary feeding for ASI 6-12 months of age is often a problem for families, generally families choose fast food, while self-cooking takes longer, this also occurs in the people of the Kotabaru sub-district area so education needs to be done to mothers who have babies less than 6 months old so they can prepare the right MP-ASI for their children later.
\end{abstract}

Keywords: children, education, MP-ASI

Abstrak
Indonesia termasuk dalam kelompok negara dengan tingkat prevalensi stunting tinggi (3039\%) dimana prevalensi ini meningkat dari 36,8\% pada tahun 2007 menjadi 37,2\% pada tahun 2013. Menurut UNICEF, faktor tidak langsung yang menyebabkan stunting adalah pola asuh makan (ASI-Eksklusif dan Makanan Pendamping ASI) yang tidak baik. Beberapa penelitian menyatakan bahwa masalah gizi pada bayi dan anak disebabkan kebiasaan pemberian ASI dan MP-ASI yang tidak tepat. Pemberian makananan pendamping ASI usia 6-12 bulan seringkali menjadi suatu hal yang merepotkan bagi keluarga, umumnya keluarga memilih makanan cepat saji, sementara memasak sendiri perlu waktu yang lebih lama, hal ini juga terjadi pada masyarakat wilayah kecamatan Kotabaru sehingga perlu dilakukan edukasi kepada ibu yang memiliki bayi usia kurang dari 6 bulan agar dapat menyiapkan MP-ASI yang tepat untuk anaknya kelak.

Kata Kunci: Bayi, MP-ASI, pendidikan

\section{PENDAHULUAN}

Keadaan status gizi usia di bawah dua tahun (Baduta) merupakan kelompok yang rawan gizi dan akan menentukan kualitas hidup selanjutnya. Permasalahan gizi di Indonesia yang semakin meningkat tiap tahun adalah malnutrisi pada Balita antara lain gizi kurang, gizi buruk, dan stunting (anak pendek).

Indonesia termasuk dalam kelompok negara dengan tingkat prevalensi stunting tinggi (30-39\%) dimana prevalensi ini meningkat dari 36,8\% pada tahun 2007 menjadi 37,2\% pada tahun 2013 (Riskesdas, 2013)

Penyebab utama stunting masih belum jelas dan diyakini berasal dari interaksi banyak faktor. Menurut UNICEF, stunting disebabkan oleh faktor langsung yaitu rendahnya jumlah dan kualitas zat gizi yang dikonsumsi sejak dalam kandungan dan penyakit infeksi terutama infeksi saluran cerna. Selain itu, faktor tidak langsung yang menyebabkan stunting adalah pola asuh makan (ASI-Eksklusif dan 
Makanan Pendamping ASI) yang tidak baik dan rendahnya hygiene sanitasi lingkungan. (UNICEF, 2014).

Untuk mencapai hal tersebut, Strategi Nasional Peningkatan Pemberian ASI dan MP-ASI merekomendasikan pemberian makanan yang baik dan tepat bagi bayi dan anak 0-24 tahun adalah: (1) mulai menyusu dalam 1 jam setelah lahir; (2) pemberian ASI secara eksklusif sampai usia 6 bulan; (3) memberikan Makanan Pendamping ASI (MP-ASI) mulai usia 6 bulan; (4) Meneruskan pemberian ASI sampai Usia 2 tahun atau lebih (Kemenkes, 2006)

dengan pendekatan yang lebih komunikatif sesuai dengan tingkat pendidikan dan kemampuan masyarakat. Selain itu, ibu-ibu kurang menyadari bahwa setelah bayi berumur 6 bulan memerlukan MP-ASI dalam jumlah dan mutu yang semakin bertambah, sesuai dengan pertambahan umur bayi dan kemampuan alat cernanya (Handayani, 2006).

Bayi dengan usia diatas 6 bulan harus diberikan Makanan Pendamping Air Susu Ibu (MP-ASI) dalam jumlah yang cukup baik dari segi kuantitas maupun kualitas. Jika bayi dan anak usia 6-24 bulan tidak memperoleh cukup gizi dari MP-ASI, maka akan mengakibatkan gangguan pertumbuhan dan kurang gizi. Oleh karena itu mengatasi untuk masalah masalah kekurangan gizi maka diperlukan perbaikan pada kuantitas dan kualitas MP-ASI.

Banyak ibu yang belum mengerti akan pentingnya gizi badutanya. Pemberian makananan pendamping ASI (MP-ASI) usia 6-12 bulan seringkali menjadi suatu hal yang merepotkan bagi keluarga, umumnya keluarga memilih makanan cepat saji, sementara memasak sendiri perlu waktu yang lebih lama, hal ini juga terjadi pada masyarakat wilayah kecamatan Kotabaru.

Berdasarkan uraian latar belakang diatas diperlukan pendidikan kesehatan pada ibu-ibu yang memiliki bayi dan balita tentang pengolahan dan pemberian Makanan Pendamping ASI (MP-ASI) yang
Para ahli sepakat bahwa praktik pemberian makan yang baik dan tepat sangat penting untuk pertumbuhan dan perkembangan bayi dan anak. Beberapa penelitian menyatakan bahwa masalah gizi pada bayi dan anak disebabkan kebiasaan pemberian ASI dan MP-ASI yang tidak tepat (segi kuantitas dan kualitas). Jika bayi dan anak usia 6-24 bulan tidak memperoleh cukup gizi dari MP-ASI, maka akan mengakibatkan gangguan pertumbuhan dan kurang gizi. Keadaan ini memerlukan penanganan tidak hanya dengan penyediaan pangan, tetap

tepat sehingga dapat mencegah gangguan gizi dan terjadinya stunting.

\section{TARGET DAN LUARAN}

\section{Target}

Untuk memperoleh MP-ASI yang baik secara kuantitas dan kualitas maka diperlukan peranan petugas kesehatan dalam memberikan pendidikan kesehatan kepada ibu, pengasuh dan keluarga sehingga diperoleh perubahan perilaku dalam menyiapkan MP-ASI. Oleh karena itu diperlukan peningkatan pengetahuan dan keterampilan ibu bayi/ Baduta melalui kegiatan konseling, penyuluhan dan praktik pembuatan MP-ASI.

\section{Luaran}

Adapun luaran kegiatan pengabdian ini adalah publikasi pada jurnal ilmiah dan peningkatan pengetahuan dan keterampilan ibu bayi/ Baduta tentang:

a. Pengertian infeksi masa nifas

b. Penyebab infeksi masa nifas

c. Tanda dan gejala infeksi masa nifas

d. Pencegahan infeksi masa nifas

Hasil akhir dari kegiatan ini diharapkan dapat menurunkan prevalensi status gizi kurang dan gizi buruk (KEP) serta stunting pada balita akibat praktek pemberian MP ASI yang kurang tepat.

\section{METODE PELAKSANAAN}

Kegiatan pengabdian kepada masyarakat dilaksanakan pada bulan 
Oktober sampai dengan Januari 2019 sasaran kegiatan adalah ibu yang mempunyai Bayi di Wilayah Kerja Puskesmas Kenali Besar Kota Jambi.

Tahapan kegiatan pengabdian kepada masyarakat meliputi :

\section{Persiapan}

1. Sosialisasi : Pertemuan dengan Kepala Puskesmas dan Bidan Koordinator Puskesmas Kenali Besar Kota Jambi, kemudian mengurus administrasi dan menyepakati jadwal pelaksanaan pengabdian masyarakat.

2. Mengidentifikasi masalah

3. Perumusan solusi : memberikan pendidikan kesehatan kepada ibu bayi/ Baduta melalui kegiatan konseling, penyuluhan dan praktik pembuatan MP-ASI

Pelaksanaan

1. Melakukan pretest (menggali pemahaman ibu hamil tentang pembuatan MP-ASI.

2. Memberikan pendidikan kesehatan tentang pembuatan MP-ASI.

\section{HASIL DAN PEMBAHASAN}

Kegiatan penyuluhan ini bertujuan agar ibu memahami bagaimana cara pengolahan MP-ASI yang tepat sehingga tidak merusak kandungan Selain itu diharapkan ibu hamil dapat mengidentifikasi tanda gejala infeksi, sehingga apabila mengalaminya dapat segera konsultasi ke petugas kesehatan.

Kegiatan hari pertama adalah melakukan pendidikan kesehatan berupa penyuluhan tentang MP-ASI dan tahapan pemberiannya sesuai dengan usia bayi. Dari pemberian materi ini diharapkan ibu mengerti tentang bagaimana menentukan tahapan pemberian MP-ASI sesuai perkembangan saluran cerna bayi dan pengenalan bahan makanan diawal pemberian MP-ASI, sehingga bayi dapat beradaptasi dari makanan cair ke makanan padat.

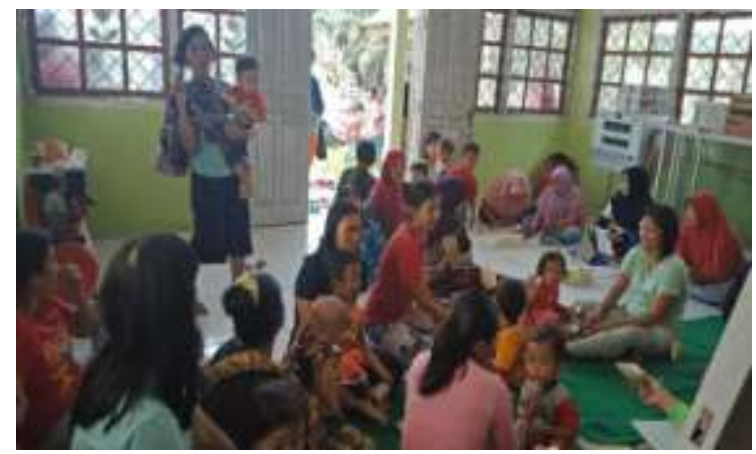

Gambar 1. Penyuluhan kesehatan

Hari kedua tim melakukan pendidikan kesehatan lanjutan tentang tanda gejala infeksi masa nifas dan pencegahan infeksi masa nifas. Ibu hamil terlihat antusias ditunjukkan dengan menyimak dan bertanya, terutama ibu dengan kehamilan pertama dimana ia belum pernah mengalami masa nifas.

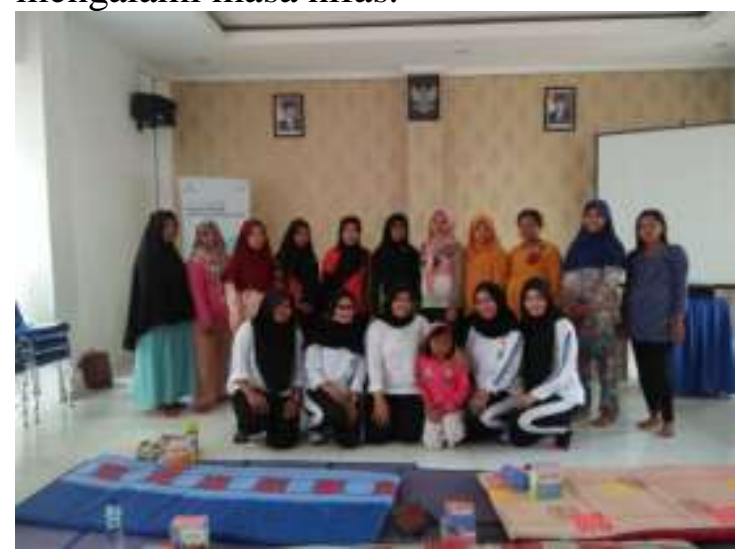

Gambar 2. Peserta Pendidikan Kesehatan Tentang Personal Hygiene Pada Masa Nifas

\section{KESIMPULAN DAN SARAN}

\section{Kesimpulan}

Pelaksanaan pengabdian masya-rakat yang dilakukan oleh dosen STIKBA tentang personal hygiene pada masa nifas berjalan dengan lancar dan didukung penuh oleh pihak Puskesmas. Ibu hamil mengerti tentang penyebab, tanda gejala dan pencegahan infeksi masa nifas melalui personal hygiene yang baik.

\section{Saran}

1. Melakukan kegiatan secara rutin pada setiap ibu hamil trimester III yang berkunjung ke puskesmas sehingga semua ibu hamil mengerti tentang perawatan kebersihan masa 


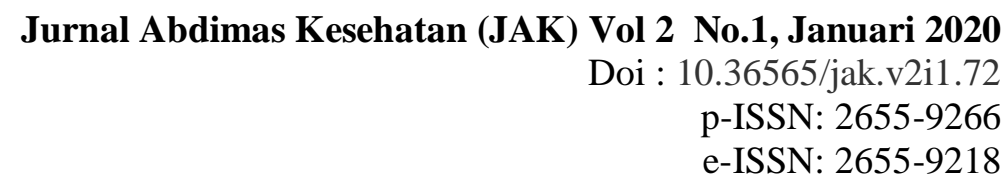

nifas.

2. Memasukkan materi pencegahan infeksi masa nifas dalam kurikulum kelas ibu di puskesmas.

3. Mengajukan kepada institusi pendidikan perguruan tinggi agar dapat mengatur jadwal kegiatan pengabdian masyarakat dengan mengajak mahasiswa dalam kegiatan penyuluhan.

\section{UCAPAN TERIMAKASIH}

Ucapan terimakasih Kami sampaikan kepada Sekolah Tinggi Ilmu Kesehatan Baiturrahim yang telah menfasilitasi kegiatan ini, kepada Bapak Kepala Puskesmas Putri Ayu Kota Jambi beserta jajarannya yang banyak membantu kegiatan ini, ibu hamil yang berkunjung di Puskesmas Putri Ayu yang bersedia menjadi peserta kegiatan pengabdian masyarakat ini.

\section{DAFTAR PUSTAKA}

Dama. Dian, 2015. Asuhan Kebidanan Masa Nifas. Refika Aditama. Bandung

Dinkes Kota Jambi. 2016. Data Ibu Antenatal di Puskesmas Kota Jambi Tahun 2015-2016. Jambi

Elisabeth dkk. 2015. Asuhan Kebidanan Masa Nifas Dan Menyusui. Penerbit Pustaka Baru Press. Jakarta

Prasetya Lestari. 2016. Usia Berpengaruh Dominan terhadap Perilaku Perawatan Luka Perineum pada Ibu Nifas. Yogyakarta

Puskesmas Putri Ayu. 2017. Profil Puskesmas. Jambi

Reni. 2015. Asuhan Kebidanan Masa Nifas Dan Menyusui. Penerbit CV. Trans Info Media. Jakarta

Saleha. 2009. Asuhan Kebidanan Nifas. Salemba Medika. Jakarta

Sarwono. 2009. Ilmu Kebidanan. Penerbit PT Bina Pustaka. Jakarta 